\title{
MRSA Point Prevalence among Health Care Workers in German Rehabilitation Centers: A Multi-Center, Cross-Sectional Study in a Non-Outbreak Setting
}

\author{
Melanie Schubert ${ }^{1, *(1)}$, Daniel Kämpf ${ }^{1}$, Marlena Wahl ${ }^{1}$, Samuel Hofmann ${ }^{1}$, Maria Girbig ${ }^{1}$, \\ Lutz Jatzwauk $^{2}$, Claudia Peters ${ }^{3}$, Albert Nienhaus ${ }^{3,4}$ and Andreas Seidler ${ }^{1}$ \\ 1 Institute and Policlinic of Occupational and Social Medicine, Medical Faculty Carl Gustav Carus, \\ Technische Universität Dresden, 01307 Dresden, Germany; daniel.kaempf@tu-dresden.de (D.K.); \\ marlenawahl@yahoo.com (M.W.); samuel.hofmann@tu-dresden.de (S.H.); \\ maria.girbig@tu-dresden.de (M.G.); andreas.seidler@mailbox.tu-dresden.de (A.S.) \\ 2 Department of Hospital Infection Control, Medical Faculty Carl Gustav Carus, \\ Technische Universität Dresden, 01307 Dresden, Germany; lutz.jatzwauk@uniklinikum-dresden.de \\ 3 Competence Centre for Epidemiology and Health Services Research for Healthcare Professionals (CVcare). \\ University Medical Centre Hamburg-Eppendorf (UKE), 20251 Hamburg, Germany; c.peters@uke.de (C.P.); \\ albert.nienhaus@bgw-online.de (A.N.) \\ 4 Department of Occupational Medicine, Public health and Hazardous Substances, Institution for Statutory \\ Accident Insurance and Prevention in the Health and Welfare Services, 22089 Hamburg, Germany \\ * Correspondence: melanie.schubert@tu-dresden.de; Tel.: +(49)-0351-3177-456
}

Received: 27 March 2019; Accepted: 9 May 2019; Published: 13 May 2019

\begin{abstract}
People working in health care services have an increased risk of being infected with methicillin-resistant Staphylococcus aureus (MRSA), though little is known about the prevalence in rehabilitation centers. This cross-sectional study investigated the MRSA prevalence in employees from different rehabilitation centers and aimed to identify risk factors for MRSA transmission. We invited all staff (i.e., with and without patient contact from 22 participating rehabilitation centers; $n=2499$ ) to participate. Study participation included a questionnaire on personal characteristics, lifestyle, personal and occupational risk factors for MRSA and nasal swabs taken by the study team. In total, 1005 persons participated in the study (response: $40.2 \%$ ). Only four participants carried MRSA (0.40 (95\% CI 0.00-1.00) per 100). MRSA carriage did not seem to be occupationally related, as it was found in different occupations with and without direct contact with MRSA patients, as well as in different clinics with different indications and patient clientele. We could not find a clear association between MRSA carriage and potential risk factors due to the low number of cases found. Genotyping revealed the spa types t032 (Barnim epidemic strain) and t1223. Our results suggest a low point prevalence of nasal MRSA colonization in a non-outbreak setting in employees from rehabilitation centers.
\end{abstract}

Keywords: health care workers; MRSA prevalence; rehabilitation centers; non-outbreak; risk factors

\section{Introduction}

Multi-resistant bacteria, such as the methicillin-resistant Staphylococcus aureus (MRSA), are important causes of nosocomial infections worldwide [1]. Whereas sufficient data for MRSA prevalence exist for acute care hospitals, this topic has been investigated only sparsely in rehabilitation centers. Rehabilitation centers usually provide care for patients that require further treatment to recover physiological or neurological functions, or to learn how to cope with residual impairments. Rehabilitation usually follows a holistic approach and is characterized by individuality, complexity, 
and multidisciplinarity. Thus, strict isolation of patients with MRSA (as in acute care hospitals) is usually not feasible for successful rehabilitation. For this reason, patients with MRSA might be refused by rehabilitation centers, and thus receive their rehabilitation late or not at all [2]. The handling of patients with MRSA has been subject to many debates, and recommendations have been proposed by several institutions [3-6]. In sum, an individual medical risk analysis with the aim to establish an optimal compromise between measures for the prevention of MRSA transmission and rehabilitation participation is recommended. Great emphasize is put on hygiene measures for staff and the patients. However, it has been shown that additional hygienic measures carry an additional substantial financial burden for rehabilitation centers, thereby lowering resources for rehabilitative core services [7].

Rehabilitation centers are often characterized by higher staff-patient contacts due to therapeutic measures. So far, there is only little data available for MRSA prevalence in health care workers (HCWs) in rehabilitation centers. A pooled analysis of studies from non-outbreak settings in Europe and the US showed a prevalence of MRSA carriage in HCWs of 1.8\% (95\% CI 1.34-2.50) [8]. In particular, Heudorf and colleagues observed MRSA prevalence of $0.6 \%$ in staff members from a German nursing home and geriatric rehabilitation unit. An Italian point prevalence study on MRSA colonization in wards with a mix of neurological, orthopedic, post-coma, and spinal cord injury cases found a prevalence of 3.1\% [9]; this study observed MRSA colonization only among nurses but not among other HCWs. Moreover, a French study observed a MRSA prevalence of $10 \%$ among HWC staff and $20 \%$ among patients [10]. The highest MRSA prevalence was observed in assistant nurses, and occupations with more physical contact with patients were associated with a higher MRSA prevalence. The aim of this study was to determine the prevalence of MRSA in employees of different rehabilitation centers in a large multi-center setting in Germany and to identify risk factors for MRSA colonization.

\section{Materials and Methods}

The study was conducted from September 2016 to May 2018. Ethical approval was obtained from the ethics committee of the TU Dresden (Clearance number EK 247062016). Methods were tested a priori with a pilot study in an acute care hospital in Dresden [11].

First, 34 rehabilitation centers in Saxony were invited, of which 10 participated in the study. These 10 rehabilitation centers employed 1173 persons altogether, of which 447 (38.1\%) participated in the study. Twenty-four rehabilitation centers in Saxony refused to participate. Reasons for not participating, if named, were as follows: basic refusal to participate in studies of any kind $(n=1)$, not desired by the clinic management without specification $(n=3)$, fear regarding how to handle colonized staff and fear that a large number of employees would be on sick leave $(n=1)$, no one would participate $(n=1)$, expected high time expenditure $(n=1)$, no interest $(n=1)$, and no time $(n=1)$. Second, 66 rehabilitation centers from neighboring federal states, (i.e., Bavaria, Brandenburg, Saxony-Anhalt, and Thuringia) were also invited. Of these, 11 institutions participated in the study. One rehabilitation center contacted us through its own initiative.

In total, 22 German rehabilitation centers from different fields participated in the study. Specializations included addictions, cardiology, dermatology, gastroenterology, geriatrics, internal medicine, lymphology, mental trauma disorders, metabolic diseases, musculoskeletal disorders, neurology, orthopedics, oncology, pneumology, psychosomatics, psychotherapy, psychiatry, and rheumatic diseases. The number of employees within the rehabilitation centers ranged from 65-240.

The study process began with an anonymous invitation that was distributed to all employees of a participating rehabilitation center. The invitation included information about the study, an informed consent form, and a questionnaire. Standard questions on personal characteristics (e.g., gender, age, etc.) and work, as well as questions concerning occupational and personal risk factors for MRSA were incorporated into the questionnaire. Questions concerning MRSA risk factors were predominately derived from a review by Albrich and Harbarth [12], a questionnaire used for staff in nursing homes by the German Social Accident Insurance Institution for the Health and Welfare Services (Berufsgenossenschaft für Gesundheitsdienst und Wohlfahrtspflege-BGW) [13], and additional 
literature. Furthermore, an on-site information event performed by the study team was offered to each rehabilitation center.

For sampling of nasal swabs, the study team was on-site at the rehabilitation centers for 1-2 days. Participants were invited to an examination room, which was provided by each clinic. Before any measurements were taken, the informed consent and the completed questionnaire were collected and participants had an opportunity for asking questions. Then, samples were taken by a trained member of the study team using a swab from the anterior nares, which have been shown to be the main reservoir for MRSA [8]. Participants had the choice to either participate anonymously or to receive feedback of their MRSA status by mail to their private address.

Prior to the study, training seasons for sampling of nasal swabs were conducted. Samples were usually taken by the study physician (DK) or prospective physicians (MW, SH). Sampling was done in both nostrils using sterile transystem ${ }^{\circledR}$ cotton swabs (Hain LIFEscience GmbH, Nehren, Germany). One swab was used for both nostrils. Swab samples were analyzed by the Ostsächsische Labor according to the quality guidelines of the lab. The lab is accredited according to DAkkS: DIN EN ISO 15189. Prior to investigation of MRSA presence, broth enrichment media and MRSA selective agar plus non-selective blood agar were used in parallel. Swabs were plated on chromogenic agar plates selective for MRSA (BD BBL CHROMagar) and non-selective blood agar (Trypticase soy agar II with $5 \%$ sheep blood). In the case of no growth on the selective or blood agar, the enrichment broth was plated on the selective agar to culture low MRSA cell numbers. Suspicious colonies underwent phenotypical confirmation using an immunochromatic qualitative PBP2a assay (Alere) as well as antimicrobial susceptibility testing to measure MICs of oxacillin and cefoxitin using broth microdilution tests. In most cases, one single isolate was tested for MRSA unless colonies with different morphologies were present either on the selective or blood agar plate. Only S. aureus isolates suspicious for MRSA were further tested in the study and data concerning spa types of MSSA can therefore not be presented. Suspect MRSA isolates were definitively identified by the German National Reference Center for Staphylococci and Enterococci (Nationales Referenzzentrum für Staphylokokken und Enterokokken) in Wernigerode, Germany. The presence of mecA was detected in all samples.

Descriptive statistics are shown for all data. Odds ratios and 95\% confidence intervals were calculated using the exact method in Stata (StataCorp. 2011. Stata Statistical Software: Release 12. StataCorp LP, College Station, TX, USA).

Overall, 2499 employees were invited, of which 1005 participated in the study. Thus, the response rate was $40.2 \%$. Within rehabilitation centers there was a huge variation in response rates, ranging from $15.2 \%$ to $75.0 \%$. Most participants received the feedback by mail $(n=988)$; only 17 persons participated anonymously in the study.

\section{Results}

\subsection{Charcterization of the Study Population}

Mainly women participated in the study (82\%, Table 1). Most participants were between 50 and 59 years old (31.2\%) and were secondary school graduates (49.6\%). Participants predominately lived in a partnership (78.8\%). Mostly therapists (33.9\%) participated in the study with a professional experience of $15-30$ years (34.1\%). Only about one-third (32.3\%) reported having had close patient contact within the last four weeks. 
Table 1. Participant characteristics and methicillin-resistant Staphylococcus aureus (MRSA) risk factors.

\begin{tabular}{|c|c|c|}
\hline Characteristics & Number & Percent \\
\hline Total & 1005 & 100 \\
\hline \multicolumn{3}{|l|}{ Sex } \\
\hline Female & 824 & 82.0 \\
\hline Male & 175 & 17.4 \\
\hline Not reported & 6 & 0.6 \\
\hline \multicolumn{3}{|l|}{ Age in years } \\
\hline$<20$ & 6 & 0.6 \\
\hline $20-29$ & 104 & 10.3 \\
\hline 30-39 & 229 & 22.8 \\
\hline $40-49$ & 243 & 24.2 \\
\hline 50-59 & 314 & 31.2 \\
\hline$\geq 60$ & 88 & 8.8 \\
\hline Not reported & 21 & 2.1 \\
\hline \multicolumn{3}{|l|}{ Education } \\
\hline Secondary school graduation & 498 & 49.6 \\
\hline High school, university entrance qualification & 440 & 43.8 \\
\hline Other & 56 & 5.6 \\
\hline No degree & 1 & 0.1 \\
\hline Not reported & 10 & 1.0 \\
\hline \multicolumn{3}{|l|}{ Occupation } \\
\hline Physician & 104 & 10.3 \\
\hline Nurse & 140 & 13.9 \\
\hline Therapist & 338 & 33.6 \\
\hline Medical technical assistant & 28 & 2.8 \\
\hline Transport service workers & 3 & 0.3 \\
\hline Cleaner & 49 & 4.9 \\
\hline Administrative personnel & 148 & 14.7 \\
\hline Others & 186 & 18.5 \\
\hline Not reported & 9 & 0.9 \\
\hline \multicolumn{3}{|l|}{ Professional experience in years } \\
\hline$\leq 1$ & 73 & 7.3 \\
\hline $1-5$ & 232 & 23.1 \\
\hline $6-10$ & 145 & 14.4 \\
\hline $11-20$ & 111 & 11.0 \\
\hline $21-40$ & 343 & 34.1 \\
\hline$>41$ & 95 & 9.5 \\
\hline Not reported & 6 & 0.6 \\
\hline \multicolumn{3}{|l|}{ Partnership } \\
\hline Yes & 792 & 78.8 \\
\hline No & 200 & 19.8 \\
\hline Not reported & 13 & 1.3 \\
\hline \multicolumn{3}{|l|}{ Household Size } \\
\hline One-person & 199 & 19.8 \\
\hline Multi-person & 792 & 78.8 \\
\hline Not reported & 14 & 1.4 \\
\hline
\end{tabular}


Table 1. Cont.

\begin{tabular}{|c|c|c|}
\hline Characteristics & Number & Percent \\
\hline \multicolumn{3}{|l|}{ Work-related MRSA risk factors } \\
\hline \multicolumn{3}{|l|}{$\begin{array}{l}\text { Close contact with patients within the last } 4 \text { weeks } \\
\text { (washing, dressing, changing bandages, etc.) }\end{array}$} \\
\hline Yes & 325 & 66.3 \\
\hline No & 666 & 32.3 \\
\hline Not reported & 14 & 1.4 \\
\hline \multicolumn{3}{|l|}{ Contact with MRSA patients within the last 4 weeks } \\
\hline Yes & 136 & 13.5 \\
\hline No & 320 & 31.8 \\
\hline Unknown & 542 & 53.9 \\
\hline Not reported & 7 & 0.7 \\
\hline \multicolumn{3}{|l|}{ Wearing protective gear when having contact with } \\
\hline \multicolumn{3}{|l|}{ MRSA patients } \\
\hline Yes, always & 104 & 76.5 \\
\hline Occasionally without & 30 & 22.1 \\
\hline Not reported & 2 & 1.5 \\
\hline \multicolumn{3}{|l|}{ Protective gear worn when having contact with } \\
\hline \multicolumn{3}{|l|}{ MRSA patients } \\
\hline Surgical face mask, disposable gloves, and lab coat & 79 & 58.1 \\
\hline Surgical face mask and disposable gloves & 12 & 8.8 \\
\hline Disposable gloves & 11 & 8.1 \\
\hline Disposable gloves and lab coat & 2 & 1.5 \\
\hline Surgical face mask and lab coat & 1 & 0.7 \\
\hline Not applicable & 2 & 1.5 \\
\hline None reported & 29 & 21.3 \\
\hline \multicolumn{3}{|l|}{ Working abroad } \\
\hline Yes & 15 & 1.5 \\
\hline No & 978 & 97.3 \\
\hline Not reported & 12 & 1.2 \\
\hline \multicolumn{3}{|l|}{ Private life-related MRSA risk factors } \\
\hline \multicolumn{3}{|l|}{ Caring for relatives at home } \\
\hline Yes & 72 & 7.2 \\
\hline No & 926 & 92.1 \\
\hline Not reported & 7 & 0.7 \\
\hline \multicolumn{3}{|l|}{ Contact with MRSA carriers } \\
\hline Yes & 14 & 1.4 \\
\hline No & 535 & 53.2 \\
\hline Unknown & 449 & 44.7 \\
\hline Not reported & 7 & 0.7 \\
\hline \multicolumn{3}{|l|}{$\begin{array}{l}\text { Contact with persons in need of care within the last } 4 \\
\text { weeks }\end{array}$} \\
\hline Yes & 137 & 13.6 \\
\hline No & 863 & 85.9 \\
\hline Not reported & 5 & 0.5 \\
\hline \multicolumn{3}{|l|}{$\begin{array}{l}\text { Working in the ambulant sector outside of work at } \\
\text { rehabilitation center }\end{array}$} \\
\hline Yes & 16 & 1.6 \\
\hline No & 984 & 97.9 \\
\hline Not reported & 5 & 0.5 \\
\hline \multicolumn{3}{|l|}{ Contact with farm animals } \\
\hline Yes & 89 & 8.9 \\
\hline No & 910 & 90.5 \\
\hline Not reported & 6 & 0.6 \\
\hline \multicolumn{3}{|l|}{ Contact with pets } \\
\hline Yes & 615 & 61.2 \\
\hline No & 387 & 38.5 \\
\hline Not reported & 3 & 0.3 \\
\hline
\end{tabular}


Table 1. Cont

\begin{tabular}{|c|c|c|}
\hline Characteristics & Number & Percent \\
\hline \multicolumn{3}{|c|}{ Risk factors associated with health status } \\
\hline \multicolumn{3}{|l|}{ Chronic skin disease } \\
\hline Yes, own diagnosis & 14 & 1.4 \\
\hline Yes, doctor's diagnosis & 97 & 9.7 \\
\hline No & 876 & 87.2 \\
\hline Not reported & 18 & 1.8 \\
\hline \multicolumn{3}{|l|}{ Chronic respiratory disease } \\
\hline Yes, own diagnosis & 25 & 2.5 \\
\hline Yes, doctor's diagnosis & 90 & 9.0 \\
\hline No & 869 & 86.5 \\
\hline Not reported & 21 & 2.1 \\
\hline \multicolumn{3}{|l|}{ Diabetes mellitus } \\
\hline Yes, own diagnosis & 2 & 0.2 \\
\hline Yes, doctor's diagnosis & 25 & 2.5 \\
\hline No & 951 & 94.6 \\
\hline Not reported & 27 & 2.7 \\
\hline \multicolumn{3}{|l|}{ Previous MRSA carriage } \\
\hline Yes & 17 & 1.7 \\
\hline No & 983 & 97.8 \\
\hline Not reported & 5 & 0.5 \\
\hline \multicolumn{3}{|c|}{ Use of antibiotics within the last 12 months } \\
\hline Yes & 304 & 30.2 \\
\hline No & 690 & 68.7 \\
\hline Not reported & 11 & 1.1 \\
\hline \multicolumn{3}{|c|}{ Having had an operation within the last 30 days } \\
\hline Yes & 40 & 4.0 \\
\hline No & 959 & 95.4 \\
\hline Not reported & 6 & 0.6 \\
\hline \multicolumn{3}{|c|}{ Inpatient hospital treatment within the last 12 months } \\
\hline Yes & 95 & 9.5 \\
\hline No & 902 & 89.8 \\
\hline Not reported & 8 & 0.8 \\
\hline
\end{tabular}

Having contact with MRSA-patients within the last four weeks was reported by $13.5 \%$, of which the majority $(76.5 \%)$ also reported wearing protective gear at all times; $22.1 \%$ of participants had occasional contact without protective clothing, and two participants did not answer the question. When having contact with MRSA patients, the majority of participants (58.1\%) reported wearing a surgical face mask, disposable gloves, and a lab coat.

In terms of private life risks, only a few participants had known contact with MRSA carriers (1.4\%). Approximately $7.2 \%$ were caring for relatives at home and $13.6 \%$ had contact with persons in need of care within the last 4 weeks. Only 16 of 1005 reported working in the ambulant sector besides their work at the rehabilitation center. The majority of participants had contact with pets $(61.2 \%)$. Contact with farm animals was reported by $8.9 \%$.

Seventeen of 1005 participants had previously had MRSA in the past. About one-third (30.2\%) of participants used antibiotics within the last 12 months. A hospital stay within the last 12 months was reported by $9.5 \%$, and $4.0 \%$ had an operation within the last 30 days. About $10 \%$ reported suffering from chronic skin disease or chronic respiratory disease. Characteristics of study population are displayed in Table 1.

\subsection{Prevalence of MRSA and Risk Factors}

Four of 1005 participants tested positive as MRSA carriers during the examination, corresponding to a prevalence of $0.40 \%$ (95\% CI 0.00-1.00). MRSA carriage was found in four different clinics with the following specializations: geriatrics, neurology, psychosomatics, and cardiology/oncology/gastroenterology. The MRSA carriers were working as a physician $(n=1)$ or as a cleaning staff member $(n=1)$, and the two remaining MRSA carriers stated having a job not listed in the questionnaire (i.e., geriatrics and psychosomatics, without any further specification). 
Professional experience ranged between MRSA carriers from less than 1 year $(n=1), 1-5$ years $(n=1)$, 6-10 years $(n=1)$, and 15-30 years $(n=1)$. Three MRSA carriers were women and one was a man.

Two of the MRSA carriers had close contact with patients and MRSA patients within the last 4 weeks.

The contact with MRSA patients was always with protective work clothing (surgical face mask, disposable gloves, and lab coat). Two of the MRSA carriers did not know if they had contact with patients with MRSA.

One MRSA carrier reported working in the Czech Republic within the last 12 months. Regarding private-life factors, none of the four MRSA carriers were caring for relatives at home, had contact with MRSA carriers or with persons in need of care within the last 4 weeks, or worked in the ambulant sector outside work. Only one of the four MRSA carriers had contact with pets and none had contact with farm animals. For risk factors associated with health status, the following picture emerged: none of the MRSA carriers had a chronic skin or respiratory disease, diabetes mellitus, used antibiotics, or had an inpatient hospital stay within the last 12 months. One MRSA carrier had an operation within the last 30 days. Another carrier had a history of MRSA colonization.

Altogether, we could not find a clear association between MRSA carriage and potential risk factors due to the low sample size. We could not clearly identify risk factors for MRSA carriage, but the results did not contradict previous risk factor research. Having contact with patients with MRSA within the last four weeks, working abroad, previous MRSA carriage, and an operation within the last 30 days may increase the risk of MRSA carriage. Results are presented in Table 2.

Table 2. Prevalence (odds ratios (ORs)) for MRSA risk factors.

\begin{tabular}{|c|c|c|c|c|c|c|}
\hline \multirow{2}{*}{ Risk Factor } & \multicolumn{2}{|c|}{ MRSA Positive (n) } & \multicolumn{2}{|c|}{ MRSA Negative $(n)$} & \multirow{2}{*}{ OR } & \multirow{2}{*}{$95 \% \mathrm{CI}$} \\
\hline & $\begin{array}{c}\text { No } \\
\text { (Reference) }\end{array}$ & Yes & $\begin{array}{c}\text { No } \\
\text { (Reference) }\end{array}$ & Yes & & \\
\hline \multicolumn{7}{|l|}{ Work-related risk factors } \\
\hline $\begin{array}{l}\text { Close contact with patients within the } \\
\text { last } 4 \text { weeks }\end{array}$ & 2 & 2 & 664 & 323 & 2.1 & $0.1-28.5$ \\
\hline $\begin{array}{l}\text { Contact with MRSA patients within the } \\
\text { last } 4 \text { weeks }\end{array}$ & 2 & 2 & 860 & 134 & 6.4 & $0.5-89.0$ \\
\hline Working abroad & 3 & 1 & 975 & 14 & 23.2 & $0.4-305.5$ \\
\hline \multicolumn{7}{|l|}{ Private life-related MRSA risk factors } \\
\hline Caring for relatives at home & 4 & 0 & 922 & 72 & - & - \\
\hline Contact with MRSA carriers & 4 & 0 & 980 & 14 & - & - \\
\hline $\begin{array}{l}\text { Contact with persons in need of care } \\
\text { within the last } 4 \text { weeks }\end{array}$ & 4 & 0 & 859 & 137 & - & - \\
\hline $\begin{array}{l}\text { Working in the ambulant sector outside } \\
\text { of work }\end{array}$ & 4 & 0 & 980 & 16 & - & - \\
\hline Contact with farm animals & 4 & 0 & 906 & 89 & - & - \\
\hline Contact with pets & 3 & 1 & 384 & 614 & 0.2 & $0.0-2.6$ \\
\hline \multicolumn{7}{|l|}{$\begin{array}{c}\text { Risk factors associated with health } \\
\text { status }\end{array}$} \\
\hline Chronic skin disease & 4 & 0 & 872 & 111 & - & - \\
\hline Chronic respiratory disease & 4 & 0 & 865 & 115 & - & - \\
\hline Diabetes mellitus & 4 & 0 & 947 & 27 & & \\
\hline Previous MRSA carriage & 3 & 1 & 980 & 16 & 20.4 & $0.4-266.8$ \\
\hline Antibiotics use within the last 12 months & 3 & 0 & 687 & 304 & - & - \\
\hline Operation within the last 30 days & 3 & 1 & 956 & 39 & 8.2 & $0.2-103.8$ \\
\hline $\begin{array}{l}\text { Inpatient hospital treatment within the } \\
\text { last } 12 \text { months }\end{array}$ & 4 & 0 & 898 & 95 & - & - \\
\hline
\end{tabular}

\subsection{MRSA Genotyping}

Genotyping revealed the MRSA spa types t032 (CC22, mecA positive) and t223 (CC22, mecA positive). The spa type 032 occurred in a clinic for geriatrics and a clinic for cardiology/oncology/ gastroenterology. The tetracycline-resistant MRSA spa type t223 was observed in a psychosomatic rehab center with psychotherapy. Unfortunately, we were unable to genotype the fourth MRSA-positive sample. 


\section{Discussion}

The present study investigated the prevalence of MRSA in 22 rehabilitation centers with different specializations. Only four of 1005 participants were colonized with MRSA $(0.4 \%, 95 \%$ CI $0.0-1.0 \%)$. This corresponds to results of the German nursing home and geriatric rehabilitation unit, which showed a prevalence of MRSA in HCWs of $0.6 \%$ [14]. For HCWs working in German acute care hospitals, prevalence rates of $2.3-5.3 \%$ have been described [15-18]. This suggests that MRSA prevalence might be generally lower in rehabilitation centers than in acute care clinics. Nevertheless, we also recently studied MRSA prevalence in an acute care hospital in a small pilot study. Here only 1 in $180(0.6 \%)$ employees, or 1 of $149(0.7 \%)$ persons with close patient contact, carried MRSA [11]. A general decrease in MRSA has been observed for Germany and Europe $[19,20]$. Thus, the low observed MRSA prevalence may also reflect this decrease.

MRSA colonization was observed in four different rehabilitation centers with the following different specialties: geriatrics, neurology, psychosomatics, and a mix of cardiac/oncological/gastroenterological cases. Geriatrics and neurology have been described as high risk units for MRSA for patients. In contrast, psychosomatic clinics and units with cardiac/oncological/gastroenterological cases are considered low risk MRSA areas [21,22]. One MRSA carrier was a physician, one worked as a cleaner, and two stated as having a job not listed in the questionnaire. Only two of the four MRSA carriers had close contact with patients and MRSA patients within the last 4 weeks (neurology and geriatrics). Thus, it is possible that MRSA transmission may have occurred indirectly. MRSA strains have a high tenacity and die off slowly (i.e., they can survive for longer than 6 months) [23]. MRSA can be found on general surfaces such as beds, floor, linen, curtains, and overbed tables [24]. Boyce and colleagues showed that environmental contamination with MRSA occurred in $69 \%$ of colonized patients [25]. Moreover, it has been shown that $42 \%$ of persons not having direct contact with MRSA patients but touching contaminated surfaces had MRSA on the gloves. This may suggest that MRSA transmission might have occurred from contaminated surfaces without having direct patient contact in two cases. Thus, strict hygiene measures, including routine disinfection of contact surfaces, are essential for limiting MRSA transmission [3,24]. However, since we do not have data on patient clientele and patient MRSA status, we cannot make an assumption about transmission pathways. Moreover, MRSA transmission may have also occurred outside the centers.

When investigating risk factors for MRSA carriage, we could not find a clear association between MRSA carriage and potential personal and occupational risk factors due to the low number of MRSA carriers in the study sample-only four HCWs carried MRSA. Nevertheless, the results are not contradictory to previous research on MRSA risk factors. Having contact with patients with MRSA within the last four weeks, working abroad, known history of MRSA carriage, and having had an operation within the last 30 days may increase the risk of MRSA carriage. These are well known risk factors for MRSA transmission in HCWs $[15,26]$.

In this study, two different MRSA spa types of the epidemic strain CC22 (mecA positive) were identified: $\mathbf{t} 032$ and $\mathbf{t} 223$. The Barnim epidemic strain (t023) was observed in the rehabilitation centers with geriatric patients and a mix of cardiological/oncological/gastroenterological cases. This strain is a classical nosocomial MRSA strain that is spread throughout Germany [20,27]. Rehabilitation centers usually provide care following treatment in an acute care hospital. Thus, the spread of MRSA between hospitals and rehabilitation centers is likely to occur. Indeed, the Barnim epidemic strain has been shown to be the second most frequent epidemic strain in patients from rehabilitation centers with neurologic, orthopedics, internal medicine, and geriatric units [28]. The spa type t223 occurred in a psychosomatic rehabilitation center. This strain is associated with community-acquired MRSA and has only been observed sporadically before 2014 [20]. A recent analysis by the Robert Koch Institute showed a trend for increasing tetra-cycline resistant MRSA in recent years, where it has been observed among asylum seekers in central reception centers [20].

One study limitation was the low response rate of $40.2 \%$. The variation in response was rather large, ranging from $15.2 \%$ to $75.0 \%$ within the single rehabilitation centers. Mainly women 
participated in the study ( $82 \%)$. Most participants were between 50-59 years (31.2\%) followed by $40-49$ years $(24.2 \%), 30-39$ years $(22.8 \%)$, under 30 years $(10.9 \%)$, and over 60 years $(8.8 \%)$. Unfortunately, we do not have information about the general employee characteristics of the rehabilitation centers. However, according to the German Federal Statistical Office (DESTATIS), about $77 \%$ of health personnel in prevention and rehabilitation centers were women in 2016 [29]. Moreover, the age structure of study participants generally corresponds to the age structure of rehabilitation staff in Germany, as monitored by DESTATIS. In the year 2016, the majority of staff working in prevention and rehabilitation centers were between $50-60$ years $(31.4 \%)$ followed by $40-50$ years $(24.0 \%), 30-40$ years $(19.0 \%)$, under 30 years $(14.9 \%)$, and over 60 years $(10.7 \%)$. Thus, the characteristics of our study population generally correspond to that of nationwide rehabilitation staff characteristics, suggesting little bias. Another limitation of the study is the lack of environmental samples in the participating centers. A further study limitation is that we only tested employees, and not patients. Data on patient MRSA status would have made it possible to test assumptions about possible transmission paths [30]. Moreover, we only sampled the anterior nares for MRSA. This may have led to an underestimation of MRSA prevalence because it has been shown that screening other body sites (e.g., throat and axilla) increases MRSA yield over nares alone [31]. The study was also underpowered due to the (unexpectedly) low sample of MRSA carriers. Due to the low prevalence of MRSA carriage in this population, a huge sample size is required to generate robust data for identifying risk factors for MRSA transmission.

\section{Conclusions}

Our results suggest a low point prevalence of MRSA in employees from German rehabilitation centers in a non-outbreak setting. MRSA carriage was a rare event found in different occupations among workers with and without direct contact with MRSA patients, as well as in different clinics with different specializations and caring for different patient clientele. Due to the low prevalence of MRSA, risk factors for MRSA carriage could not be evaluated. Altogether, the results correspond to the recently reported trend of decreasing MRSA prevalence in Europe.

Author Contributions: Conceptualization: A.S., M.S., D.K., and M.G.; methodology: A.S., M.S., D.K., and M.G.; validation: M.S., M.W., and S.H.; formal analysis: M.S.; investigation: M.S., D.K., M.W., and S.H.; data curation: M.W. and S.H.; writing_original draft preparation: M.S.; writing—review and editing: M.S., D.K., M.W., S.H., M.G., L.J., C.P., A.N., and A.S.; supervision: A.S.; project administration: M.S.

Funding: This research was funded by the Statutory Accident Insurance and Prevention in Health and Welfare Services, Hamburg, Germany.

Acknowledgments: The authors wish to extend their very special thanks to Katrin Liesk-Biskop and Philipp Heinrich for their great support during the study conduct. We thank Gilda Gudacker from the Labor Ostsachsen for support. We are grateful for the comments of the anonymous reviewers.

Conflicts of Interest: The authors declare no conflict of interest. The funders had no role in the design of the study; in the collection, analyses, or interpretation of data; in the writing of the manuscript, or in the decision to publish the results.

\section{References}

1. European Centre for Disease Prevention and Control. Antimicrobial resistance surveillance in Europe 2014. Annual Report of the European Antimicrobial Resistance Surveillance Network (EARS-Net); ECDC: Stockholm, Sweden, 2015.

2. Schweizer, C.; Hummel, M.; Klefisch, F.-R.; Stoliaroff, A. Ablehnung der Behandlung von Patienten mit MRE in Geriatrischen Kliniken und Rehabilitationseinrichtungen: Einzelfälle oder Gängige Praxis? Epidemiologisches Bulletin 2017, 50, 567-579.

3. Ruscher, C. Empfehlungen zur Prävention und Kontrolle von Methicillin-resistenten Staphylococcus aureus-Stämmen (MRSA) in medizinischen und pflegerischen Einrichtungen. Bundesgesundheitsblatt-Gesundheitsforschung-Gesundheitsschutz 2014, 57, 695-732. [CrossRef] 
4. Hergenröder, H.; Mielke, M.; Höller, C.; Herr, C. Methicillin-resistente Staphylococcus aureus (MRSA) in der medizinischen Rehabilitation. Bundesgesundheitsblatt-Gesundheitsforschung-Gesundheitsschutz 2012, 55, 1453-1464. [CrossRef]

5. Brandt, C.; Jahn-Mühl, B.; Parthé, S.; Pitten, F.; Merbs, R.; Heudorf, U. MRSA/MRE in der Rehabilitation-Empfehlungen des MRE-Netz Rhein-Main. Die Rehabil. 2012, 51, 254-258. [CrossRef] [PubMed]

6. MRE-Netzwerke in Niedersachsen. Informationen zu MRSA für Rehabilitations-Einrichtungen; Land Niedersachsen: Lower Saxony, Germany, 2015.

7. Roukens, R.; Lauster, F.; Bara, M.; Eifert, B.; Willemsen, D.; Randall, T.; Herzog, J.; Wendt, C.; Schmidt-Wilcke, T.; Knecht, S. Mehrkosten durch multiresistente Erreger in der Neurorehabilitation. Bundesgesundheitsblatt-Gesundheitsforschung-Gesundheitsschutz 2017, 60, 1075-1082. [CrossRef]

8. Dulon, M.; Peters, C.; Schablon, A.; Nienhaus, A. MRSA carriage among healthcare workers in non-outbreak settings in Europe and the United States: A systematic review. BMC Infect. Dis. 2014, 14, 363. [CrossRef]

9. Rossini, A.; Balice, M.P.; Ciotoli, L.; Guaglianone, E.; Donelli, G.; Salvia, A. Healthcare workers with methicillin-resistant Staphylococcus aureus colonization and the use of contact precautions in daily activities with patients in an Italian rehabilitation hospital: The importance of hand hygiene training. Infect. Control Hosp. Epidemiol. 2010, 31, 1097-1098. [CrossRef]

10. Legrand, J.; Temime, L.; Lawrence, C.; Herrmann, J.; Boelle, P.; Guillemot, D. Occupational determinants of methicillin-resistant Staphylococcus aureus colonization among healthcare workers: A longitudinal study in a rehabilitation center. Infect. Control Hosp. Epidemiol. 2015, 36, 767-776. [CrossRef] [PubMed]

11. Schubert, M.; Kämpf, D.; Jatzwauk, L.; Stein, A.; Strasser, R.; Dulon, M.; Nienhaus, A.; Seidler, A. Prevalence and predictors of MRSA carriage among employees in a non-outbreak setting: A cross-sectional study in an acute care hospital. J. Occup. Med. Toxicol. 2019, 14, 7. [CrossRef] [PubMed]

12. Albrich, W.C.; Harbarth, S. Health-care workers: Source, vector, or victim of MRSA? Lancet Infect. Dis. 2008, 8, 289-301. [CrossRef]

13. Peters, C.; Dulon, M.; Kleinmüller, O.; Nienhaus, A.; Schablon, A. MRSA prevalence and risk factors among health personnel and residents in nursing homes in Hamburg, Germany-a cross-sectional study. PLoS ONE 2017, 12, e0169425. [CrossRef]

14. Heudorf, U.; Bremer, V.; Heuck, D.; Brune, I.; Wichelhaus, T.A. MRSA-Prävalenz bei Bewohnern von Altenund Pflegeheimen sowie bei Patienten einer geriatrischen Rehabilitationsklinik. Hyg. Med. 2002, 27, 6-9.

15. Sassmannshausen, R.; Deurenberg, R.H.; Köck, R.; Hendrix, R.; Jurke, A.; Rossen, J.W.; Friedrich, A.W. MRSA prevalence and associated risk factors among health-care workers in non-outbreak situations in the Dutch-German Euregio. Front. Microbiol. 2016, 7, 1273. [CrossRef]

16. Kaminski, A.; Kammler, J.; Wick, M.; Muhr, G.; Kutscha-Lissberg, F. Transmission of methicillin-resistant Staphylococcus aureus among hospital staff in a German trauma centre: A problem without a current solution? Br. Jt. J. 2007, 89, 642-645. [CrossRef] [PubMed]

17. Joos, A.K. MRSA-Personalscreening in einer chirurgischen Universitätsklinik. Hyg. Med. 2009, 34, $183-187$.

18. Witte, W.; Mielke, M.; Ammon, A.; Nassauer, A.; Wischnewski, N. Fachtagung der AG nosokomiale Infektionen am RKI zur Intensivierung der Umsetzung von Präventionsstrategien bei MRSA. Epidemiol. Bull. 2005, 5, 31-38.

19. European Centre for Disease Prevention and Control. Surveillance of Antimicrobial Resistance in Europe 2016: Annual report of the European Antimicrobial Resistance Surveillance Network (EARS-Net); European Centre for Disease Prevention and Control: Stockholm, Sweden, 2017.

20. Layer, F.; Strommenger, B.; Cuny, C.; Werner, G.; Noll, I.; Sin, M.A.; Eckmanns, T. Eigenschaften, Häufigkeit und Verbreitung von MRSA in Deutschland. Epidemiol. Bull. 2018, 21, 187-193.

21. Köck, R.; Winner, K.; Schaumburg, F.; Jurke, A.; Rossen, J.; Friedrich, A. Admission prevalence and acquisition of nasal carriage of methicillin-resistant Staphylococcus aureus (MRSA) in German rehabilitation centres. J. Hosp. Infect. 2014, 87, 115-118. [CrossRef] [PubMed]

22. Neumann, N.; Mischler, D.; Cuny, C.; Hogardt, M.; Kempf, V.A.; Heudorf, U. Multiresistente Erreger bei Patienten ambulanter Pflegedienste im Rhein-Main-Gebiet 2014. Bundesgesundheitsblatt-Gesundheitsforschung-Gesundheitsschutz 2016, 59, 292-300. [CrossRef] [PubMed]

23. Wagenvoort, J.; Sluijsmans, W.; Penders, R. Better environmental survival of outbreak vs. sporadic MRSA isolates. J. Hosp. Infect. 2000, 45, 231-234. [CrossRef] 
24. Dancer, S.J. The role of environmental cleaning in the control of hospital-acquired infection. J. Hosp. Infect. 2009, 73, 378-385. [CrossRef] [PubMed]

25. Boyce, J.M.; Potter-Bynoe, G.; Chenevert, C.; King, T. Environmental contamination due to methicillin-resistant Staphylococcus aureus possible infection control implications. Infect. Control Hosp. Epidemiol. 1997, 18, $622-627$. [CrossRef]

26. Blok, H.E.; Troelstra, A.; Kamp-Hopmans, T.E.; Gigengack-Baars, A.C.; Vandenbroucke-Grauls, C.M.; Weersink, A.J.; Verhoef, J.; Mascini, E.M. Role of healthcare workers in outbreaks of methicillin-resistant Staphylococcus aureus: A 10-year evaluation from a Dutch university hospital. Infect. Control Hosp. Epidemiol. 2003, 24, 679-685. [CrossRef]

27. Becker, K.; Schaumburg, F.; Hübner, N.-O.; Köck, R. MRSA: Typisierung und Epidemiologie mit Schwerpunkt Deutschland. Krankenh. up2date 2014, 9, 93-109. [CrossRef]

28. Woltering, R.; Hoffmann, G.; Daniels-Haardt, I.; Gastmeier, P.; Chaberny, I. MRSA-Prävalenz in medizinischen und pflegerischen Einrichtungen eines Landkreises. DMW-Deutsch. Med. Wochenschr. 2008, 133, 999-1003. [CrossRef] [PubMed]

29. DESTATIS Statistisches Bundesamt. 2019. Available online: https://www.destatis.de/DE/ ZahlenFakten/GesellschaftStaat/Gesundheit/Gesundheitspersonal/Tabellen/Einrichtungen.html; jsessionid=4023D7812701EC5AF219DD1CEAF256FD.InternetLive1 (accessed on 21 January 2019).

30. Price, J.R.; Cole, K.; Bexley, A.; Kostiou, V.; Eyre, D.W.; Golubchik, T.; Wilson, D.J.; Crook, D.W.; Walker, A.S.; Peto, T.E. Transmission of Staphylococcus aureus between health-care workers, the environment, and patients in an intensive care unit: A longitudinal cohort study based on whole-genome sequencing. Lancet Infect. Dis. 2017, 17, 207-214. [CrossRef]

31. McKinnell, J.A.; Huang, S.S.; Eells, S.J.; Cui, E.; Miller, L.G. Quantifying the impact of extra-nasal testing body sites for MRSA colonization at the time of hospital or intensive care unit admission. Infect. Control Hosp. Epidemiol. 2013, 34, 161. [CrossRef]

(C) 2019 by the authors. Licensee MDPI, Basel, Switzerland. This article is an open access article distributed under the terms and conditions of the Creative Commons Attribution (CC BY) license (http://creativecommons.org/licenses/by/4.0/). 